\title{
Comparison of sleep between youth elite amateur athletes and professional athletes
}

\author{
Elina Penttilä ${ }^{1,2}\left(\mathbb{0} \cdot\right.$ Ville-Pekka Vuorinen $^{3} \cdot$ Marko Kivimäki $^{4} \cdot$ Jari Ahlberg $^{5} \cdot$ Olavi Airaksinen $^{6} \cdot$ Henri Tuomilehto $^{7}$
}

Received: 23 December 2020 / Accepted: 7 May 2021 / Published online: 23 May 2021

(c) The Author(s) 2021

\begin{abstract}
Recent studies suggest that professional athletes seem to experience significant sleeping problems. However, little is still known about the occurrence of sleeping challenges at different stages of an athletic career. This descriptive study aimed to compare the sleep of professional athletes with younger elite amateur athletes. A total of 401 sportsmen, 173 youth elite amateur athletes and 228 professional athletes fulfilled a validated questionnaire. The self-estimated quality of sleep (on a linear scale $0-10)$ was significantly better in youth, being 7.9 compared to $7.4(p<0.001)$. The professional athletes had a significantly higher risk for sleeping problems, especially during the competitive season $(\mathrm{OR}=7.3,95 \%$ confidence interval 4.1-12.9) and they also used significantly more sleep medications $(\mathrm{OR}=8.3,95 \%$ confidence interval 1.7-4.1). Interestingly, majority of youth athletes $(85.4 \%)$ had received adequate sleep counselling compared with professional athletes $(58.1 \%)$, $(p<0.001)$. Furthermore, $75.8 \%$ of professional athletes considered that additional sleep counselling would improve their performance compared with only $45.6 \%$ of youth athletes $(p<0.001)$. Our study demonstrates that compared with the younger counterparts, professional athletes experience impaired sleep quality and significantly more sleeping problems. There may be various underlying factors to induce the problems. The early intervention with sleep counselling may play an important role in preventing these problems and, therefore, it is recommended to be integrated in athletes' overall training process.
\end{abstract}

Keywords Youth elite athlete $\cdot$ Counselling $\cdot$ Sleep $\cdot$ Professional athlete

\section{Introduction}

Our well-being is based on a healthy lifestyle; regular exercise, healthy nutrition and refreshing sleep. All these elements influence each other through complex interactions. If one neglects one component, there exists a major risk

Elina Penttilä

elina.penttila@kuh.fi

1 Department of Otorhinolaryngology, University of Eastern Finland, Kuopio, Finland

2 Department of Otorhinolaryngology, Kuopio University Hospital, Kuopio, Finland

3 Terveystalo Clinical Hospital, Kuopio, Finland

4 Mehiläinen Clinical Hospital, Hämeenlinna, Finland

5 Department of Oral and Maxillofacial Diseases, Faculty of Medicine, University of Helsinki, Helsinki, Finland

6 Department of Physical and Rehabilitation Medicine, Kuopio University Hospital, Kuopio, Finland

7 Coronaria Sleep Clinics, Helsinki, Finland that it will impact the other parts, thus risking the individual's health [1]. Sleep disorders have become increasingly prevalent, it has been estimated that at least one in every five adults suffers from chronic sleep problems [2, 3]. Sleep disturbances have not only become frequent in the general population, but recent studies indicate that elite athletes are faced by multiple sleep problems [1, 4-8]. They are known to get less sleep than non-athletes, and furthermore they have longer sleep latency and lower sleep efficiency for example because of recurrent awakenings at nighttime. Also, insomnia and sensitivity of sleep are common among professional athletes $[5,9,10]$.

To be a successful athlete, one must have talent, will to train hard and ability to recover well. Therefore, the recovery provided by restorative sleep can be viewed as a cornerstone of successful training and performance for athletes. For elite amateur athletes, the frequent exposure to high-intensity training and competition programmes increases their need for recovery, and therefore may increase their overall requirement for sleep [1]. On the other hand, problems in sleeping may affect the balance of training and recovery, also 
predisposing them to overtraining [11]. Sleep deprivation has been found to be associated with athletic injuries [12] and encouraging young athletes to get optimal amounts of sleep seems to help protect them against injuries [13]. Athletes are exposed not only to major physical efforts but also to intense psychological stress. However, it seems that they are not provided with appropriate techniques to overcome their sleep problems $[4,14]$.

Sleep is not only about quantity i.e. hours spend in bed but also quality. Although some studies have investigated how long athletes sleep, a search of the literature reveals that there is limited information about the quality of their sleep and sleeping problems. Furthermore, little is known about sleep and possible challenges in sleeping at different stages of athletic career $[12,15,16]$. Several studies have demonstrated that professional athletes are facing increased risk of poor sleep and even sleep disorders are not uncommon among them [1, 4-8]. On the other hand, previous studies have also demonstrated that systematic sleep counselling can enhance the quality of athletes' sleep [1, 10, 17]. In which point the problems start to progress or do younger amateur athletes also already confront major challenges in sleeping and quality of sleep? A recent study indicated that many collegiate student athletes are not obtaining enough sleep. However, the investigators stated that more data on studentathlete sleep risk factors, sleep quality measurement, and the prevalence of sleep disorders is needed [16]. There is a definite need for studies examining athletes at different stages of their career to better understand the nature of possible challenges in sleeping. Furthermore, we need more evidence of impact of interventions, such as, sleep counselling, on athletes' sleep. This cross-sectional study aimed to compare the quality of sleep, the prevalence of sleep problems, the use of sleep medication and received sleep counselling between youth elite amateur athletes and professional athletes. We hypothesized that professional athletes encounter more difficulties in sleeping than their younger, amateur colleagues. Based on our previous studies, we also hypothesized that sleep counselling may be of importance [1].

\section{Materials and methods}

\section{Participants}

All athletes participated in sleep counselling of the study group and the sleep questionnaire used in study was essential part of the counselling and all athletes fulfilled it. No exclusion criteria were used. The sleep questionnaire was fulfilled prior to sleep counselling as a screening tool. A total of 401 athletes (368 male, 33 female) including 173 youth amateur elite amateur athletes and 228 professional athletes participated. The youth athletes were draftees of the Finnish Defence Forces Sports School $(n=173)$ representing same sport as professional athletes. The professional athletes represented national Olympic athletes, representing both summer and winter disciplines $(n=65)$, ice hockey players $(n=137)$, and soccer payers $(n=26)$; both the ice hockey and football teams represented the highest national level (Table 1). The major difference between these two groups was that for the professional athletes their regular income came from their sport compared with the youth elite amateur athletes. The study was conducted in two private sleep clinics (same physician) in collaboration with the local university. The participants were given both oral and written information about the trial and they provided signed informed consent. Approval from the Research Ethics Committee of the local University Hospital District was obtained for the study.

\section{Study design}

This descriptive study was conducted between September 2013 and September 2015. A standard clinical protocol for evaluating the sleep of athletes was used: the sleeping habits, the prevalence of sleep disturbances and problems, the use of sleep medication and previously received sleep counselling of all participants were evaluated via a questionnaire.

\section{Sleep questionnaire}

The questions in the sleep questionnaire were based on previous validated questionnaires (Basic Nordic sleep questionnaire) that have been used to screen for sleep disturbances and sleep problems with some amendments related to athletic performance [1, 18-21]. In the questionnaire, the athletes were asked to self-estimate their regular sleep duration i.e. the sum of average nocturnal sleep time from sleep onset

Table 1 Baseline demographics of the study population

\begin{tabular}{lll}
\hline & $\begin{array}{l}\text { Youth elite ama- } \\
\text { teur athletes } \\
(n=173)\end{array}$ & $\begin{array}{l}\text { Professional athletes } \\
(n=228)\end{array}$ \\
\hline $\begin{array}{l}\text { Sex } \\
\text { Male }\end{array}$ & 171 & 197 \\
Female & 2 & 31 \\
Age & $19(0.751)$ & $25.9(6.073)$ \\
& $(18-22)$ & $(16-51)$ \\
Sport & & 137 \\
Ice hockey & & 26 \\
Soccer & & 65 \\
Olympic disciplines & & \\
\hline
\end{tabular}

Data are mean values (standard deviation) or number of cases 
to wake-up (6 h or less, $7 \mathrm{~h}$, or $8 \mathrm{~h}$ or more), sleep onset time, number of nocturnal awakenings, whether they have had regular problems in sleeping during the off-season or in the competitive season (if they have experienced problems, had they taken sleep medication and if so, what medication), and if their bedfellows have noticed breathing pauses during their sleep. The following questions were recorded; (a) How often do you feel excessively sleepy during the daytime? (b) How often do you take a nap? (c) How often do you snore? (d) How often do you take sleep medication? The participants were also asked whether they have unpleasant feelings in their legs or extremities at rest and/or when lying in bed in the evening and if moving their limbs or walking can help ease these unpleasant sensations. Furthermore, the participants were asked to self-estimate the average quality of their nocturnal sleep (a linear scale of 0 to $10 ; 0=$ worst possible and $10=$ best possible). Finally, the participants were asked to assess whether they consider good sleep as being important for their athletic performance. They were also asked whether they had received previously sleep counselling and, if they considered that an additional sleep counselling would further improve their performance. The questionnaire can be found in Appendix (Supplementary Material).

\section{Statistical analysis}

Patient characteristics and variables were analysed with the Statistical Package for Social Sciences (SPSS software version 22 for Windows, SPSS Inc., Chicago, USA). Descriptive statistics were expressed as frequencies with percentages for categorical variables and with mean \pm the standard deviation (SD) for continuous variables. Differences between the groups in categorical variables were assessed using Pearson's Chi-squared test and in continuous variables with an independent samples $t$ test. The distributions of continuous variables were normally distributed. Adjusted $p$ values by age and by age and sex were calculated by a binary logistic regression model and linear regression model. The differences were regarded statistically significant if a two-sided $p$ value was less than 0.05 .

\section{Results}

A total of 401 sportsmen, 173 youth elite amateur athletes and 228 professional athletes, were included in the study. At the time of the survey, the mean age of the youth athletes was 19.5 (SD 0.751) and of the professional athletes 25.9 (SD 6.073) (Table 1).

Almost all the participants (98.3\%) considered that good sleeping is important for their performance $(92.2 \%$ of youth and of $99.1 \%$ of professional athletes, $p=0.435$ ). The selfestimated quality of sleep (on a linear scale 0 to 10 ) was significantly better among the youth atheletes, being $7.9 \mathrm{com}$ pared to 7.4 of professional athletes $(p<0.001)$. Professional athletes had a significantly higher risk for problems in sleeping $(\mathrm{OR}=4.4,95 \%$ confidence interval $2.1-9.2)$, especially during the competitive season ( $\mathrm{OR}=7.3,95 \%$ confidence interval 4.1-12.9) when almost half of professional athletes $(42.2 \%)$ had notable problems in sleeping (Fig. 1). Professional athletes also used significantly more sleep medications $(\mathrm{OR}=8.3,95 \%$ confidence interval 1.7-4.1 (Fig. 1). Breathing pauses during sleep were more evident among professional athletes $(\mathrm{OR}=14.8,95 \%$ confidence interval 1.1-112.1). All the main differences between the groups, also adjusted by age, are also shown in Table 2 .

Most youth athletes (85.4\%) had received adequate sleep counselling compared with professional athletes (58.1\%),
Fig. 1 Comparison of sleep of youth elite amateur and professional athletes. Data are percentages. Differences between the groups were assessed using Pearson's Chi-squared test

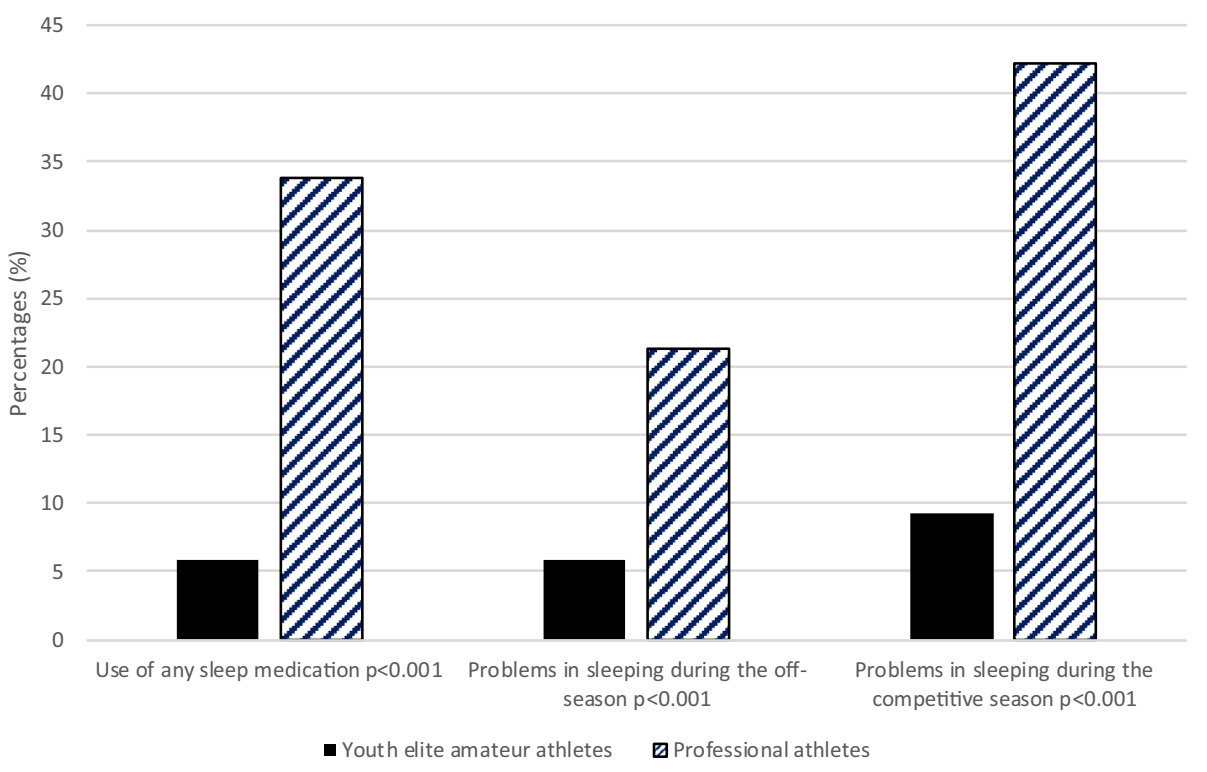


Table 2 Comparison of sleep of youth elite amateur and professional athletes

\begin{tabular}{|c|c|c|c|c|}
\hline & $\begin{array}{l}\text { Youth elite ama- } \\
\text { teur athletes }\end{array}$ & Professional athletes & $p$ value & Adjusted $p$ value* \\
\hline Self-estimated quality of sleep $(0-10)$ & $7.9 \pm 1.0$ & $7.4 \pm 1.5$ & $<0.001$ & $0.022 / 0.027$ \\
\hline Use of any sleep medication & $10(5.8 \%)$ & $76(33.9 \%)$ & $<0.001$ & $<0.001 /<0.001$ \\
\hline Problems in sleeping during the off-season & $10(5.8 \%)$ & $34(21.3 \%)$ & $<0.001$ & $0.005 / 0.005$ \\
\hline Problems in sleeping during the competitive season & $16(9.2 \%)$ & $96(42.2 \%)$ & $<0.001$ & $<0.001 /<0.001$ \\
\hline Breathing pauses during sleep & $1(0.6 \%)$ & $18(7.9 \%)$ & 0.001 & $0.021 / 0.016$ \\
\hline Good sleep is important for performance & $168(98.2 \%)$ & $226(99.1 \%)$ & 0.435 & $0.666 / 0.759$ \\
\hline Enough counseling regarding rest and sleep & $146(85.4 \%)$ & $132(58.1 \%)$ & $<0.001$ & $<0.001 /<0.001$ \\
\hline Better sleep counseling would improve their performance & $78(45.6 \%)$ & $172(75.8 \%)$ & $<0.001$ & $<0.001 /<0.001$ \\
\hline Hope for an examination and treatment of sleep problem & $21(12.3 \%)$ & $117(52.2 \%)$ & $<0.001$ & $<0.001 /<0.001$ \\
\hline
\end{tabular}

Data are mean values, number of cases (percentages), and standard deviation. Differences between the groups in categorical variables were assessed using Pearson's Chi-squared test and in continuous variables with an independent samples $t$ test

*Adjusted by age/age and sex

$(p<0.001)$. Majority of professional athletes $(75.8 \%)$ considered that additional sleep counselling would improve their performance compared with only $45.6 \%$ of youth athletes, $(p<0.001)$. Furthermore, only $12.3 \%$ of youth athletes experienced a need for more extensive sleep examination and treatment compared with $52.2 \%$ of the professional athletes, $(p<0.001)$.

There were no differences between the study groups in sleep duration (most slept 7-8 h/night), in falling asleep (in both groups more than half fell asleep generally in 10-30 $\mathrm{min}$ ), in the number of nocturnal awakenings (most woke $0-1$ times/night) or in daytime tiredness (only about $4 \%$ of all participants had tiredness for 5 to 7 days a week). In napping frequencies or durations, there were no differences between the groups, about half of all participants took naps 2 to 4 days a week and for more than half of the athletes the nap lasted 30-60 min. Snoring was also at least as common in both groups; more than $80 \%$ reported snoring in 0-2 nights per week. $95.3 \%$ of youth and $76.8 \%$ of professional athletes reported not having unpleasant feelings in their legs and there was no statistically significant difference between the groups.

\section{Discussion}

Our study demonstrates that the sleep of youth athletes is superior compared to professional athletes. The main findings were that the self-estimated quality of sleep was significantly higher in youth athletes, they had a significantly lower risk for major sleeping problems, especially during the competitive season and used less sleep medications compared with professional athletes.

Sleep has far-reaching impacts on our health and overall well-being. In athletes, a poor night's sleep may impair performance including reaction time, accuracy, strength and endurance [10,22]. Sleep deprivation can also harm cognitive functions like such as judgement and decision-making; increase the risk of exercise-related injurie; allow for the development of recurrent upper airway infections and cause chronic pain; even lead to the creation of a vicious cycle related to sleep loss, impaired recovery; increased feelings of pain that themselves predispose athletes to sleep disturbances and delay recovery from a sports-related injury e.g. a concussion [10,13, 23-26]. The present study supports the earlier findings that sleeping-related problems are indisputably common among professional athletes $[1,6]$.

We easily forget that it is only last few years that the importance of sleep on athletic performance has received the attention it deserves. Athletes are nowadays getting more and already at younger age evidence-based information about proper sleep hygiene aiming at it becoming part of everyday athletic training routines [17]. This is also supported by our finding that significantly more, nearly $90 \%$, of youth athletes reported having received adequate counselling regarding sleep compared with $60 \%$ of professional athletes. To even highlight the difference between the groups, three out of every four professional athletes experienced that an additional, better sleep counselling would improve their athletic performance compared with less than half of the youth athletes. Every second professional athlete evaluated needing more extensive medical sleep examination and treatment compared to only one out of every ten youth athlete.

An important part of the prevention of sleeping problems in athletes is to improve their overall knowledge and provide evidence-based information of the significance of restoring sleep on their performance and, on the other hand, potential consequences of insufficient sleep on health, behaviour, attention, learning and athletic performance [10, 27, 28]. Previous studies have demonstrated that systematic 
examination, counselling, and individual treatment planning can enhance the quality of athletes' sleep [1, 10, 17]. Furthermore, this information should not be limited only for athletes but also for the coaching and medical professionals to gain a precision approach.

The counselling should be focused on regular and healthy lifestyle, general sleep matters, and aims to reduce alertness and sympathetic activity in the evening $[1,10,14,29-31]$. Typical sleep hygiene strategies include for example waking up at the same time each day, constant evening routines, and avoiding stimulants and distractions [10]. Napping and banking sleep can not only serve as an effective recovery tool between training sessions which occur on the same day but can also be used as a practical solution to reduce daytime sleepiness, particularly for athletes involved in sports which require early morning training $[5,32,33]$. Even though the short-term use of sleep medication is demonstrated to be beneficial in promoting sleep, these drugs are also associated with several harmful effects, such as misuse, increased risk for amnesia and daytime drowsiness, long-term usage, the development of tolerance, and possible impacts on the next days' performance $[12,14,34]$. Therefore, it is always recommended that sleep-promoting medication must be used with caution, and this is especially true for athletes.

Sleep is a complex physiological and psychological phenomenon, and many factors may disturb it. In addition to the role of counselling in improving the sleep, there may be some other reasons behind the differences between youth and professional athletes. Although their training and competition schedules further exacerbate the deficiency of the sleep of both youth and professional athletes [5, 27, 30, 35], professional athletes may be more often exposed to extreme travel circumstances and late-night performance [36]. One important difference may be that when the sport becomes work, the mental stress and physical demands tend to increase. Furthermore, athletes often seem to forget their daily life load as many have obligations outside their sports. The amount of rest and recovery should meet these elevated needs [14]. Sleep does change over the years, becoming more superficial and disturbed, but only in elderly age. In our study, there was 6-year difference (19.5 vs 25.9) in age between the groups (Table 1). Both groups may be considered to represent young, healthy adult population. Therefore, the age difference itself cannot explain the difference between the groups.

Some limitations of the present study need to be acknowledged. Although this descriptive study has one of the largest sample sizes regarding the sleep of athletes, the number of the participants is still relatively small. In addition, in our study, sleep was evaluated by a questionnaire without any objective assessment. Due to the cross-sectional study design, one has to interpret with caution the causality of sleep and sleep counselling. We did not collect data from use of caffeine or energy drink and BMI. However, since all the participants were top athletes, there were no overweight or obese individuals among them. Although, the study groups were homogeneous, females are underrepresented in both groups. Both sexes should be included in future studies. There are well-known gender differences in sleeping in general population; therefore, these findings may not be applicable for female athletes. Although the participants represent wide variety and common sports, these results may not ably to all disciplines. In the future studies, the marital status and the amount of children of the participants should be examined. Evaluating different methods to improve the sleep of athletes and the impact of improved sleep on athletic performance should be targeted in future studies. Sleeping problems have become prevalent in general population but also among athletes and larger well-conducted studies with longer follow-up are needed.

\section{Conclusions}

Based on current knowledge, restorative sleep may be considered the cornerstone of athletes' successful recovery. Previous studies have shown that sleeping problems have become common in professional athletes. This descriptive study compared the sleep between youth elite amateur athletes and professional athletes. Our results demonstrate that younger athletes have received more sleep counselling and experience less sleeping problems. Although there may be various factors affecting the sleep, our findings indicate that early sleep counselling may play an important role in prevention of sleep problems in athletes. Therefore, sleep counselling should be recommended to be part of athletes' overall training process aiming at success.

Supplementary Information The online version contains supplementary material available at https://doi.org/10.1007/s11332-021-00780-5.

Acknowledgements We wish to thank biostatistician Tuomas Selander, who helped us with the statistical analysis, and Keith Hakso for helping with the copy editing.

Funding Open access funding provided by University of Eastern Finland (UEF) including Kuopio University Hospital.

\section{Declarations}

Conflict of interest No potential conflict of interest was reported by the authors.

Ethical approval Approval from the Research Ethics Committee of the local University Hospital District was obtained for the study.

Informed consent The participants were given both oral and written information about the trial and they provided signed informed consent. 
Open Access This article is licensed under a Creative Commons Attribution 4.0 International License, which permits use, sharing, adaptation, distribution and reproduction in any medium or format, as long as you give appropriate credit to the original author(s) and the source, provide a link to the Creative Commons licence, and indicate if changes were made. The images or other third party material in this article are included in the article's Creative Commons licence, unless indicated otherwise in a credit line to the material. If material is not included in the article's Creative Commons licence and your intended use is not permitted by statutory regulation or exceeds the permitted use, you will need to obtain permission directly from the copyright holder. To view a copy of this licence, visit http://creativecommons.org/licenses/by/4.0/.

\section{References}

1. Tuomilehto H, Vuorinen VP, Penttila E, Kivimaki M, Vuorenmaa M, Venojarvi M et al (2016) Sleep of professional athletes: underexploited potential to improve health and performance. J Sports Sci 13:1-7

2. Ohayon MM, Partinen M (2002) Insomnia and global sleep dissatisfaction in Finland. J Sleep Res 11(4):339-346

3. Ohayon MM (2008) From wakefulness to excessive sleepiness: what we know and still need to know. Sleep Med Rev 12(2):129-141

4. Juliff LE, Halson SL, Peiffer JJ (2015) Understanding sleep disturbance in athletes prior to important competitions. J Sci Med Sport 18(1):13-18

5. Lastella M, Roach GD, Halson SL, Sargent C (2015) Sleep/wake behaviours of elite athletes from individual and team sports. Eur J Sport Sci 15(2):94-100

6. Dunican IC, Walsh J, Higgins CC, Jones MJ, Maddison K, Caldwell JA et al (2019) Prevalence of sleep disorders and sleep problems in an elite super rugby union team. J Sports Sci 37(8):950-957

7. Biggins M, Purtill H, Fowler P, Bender A, Sullivan KO, Samuels $C$ et al (2020) Sleep, health, and well-being in elite athletes from different sports, before, during, and after international competition. Phys Sportsmed 30:1-9

8. Cameron AFM, Perera N, Fulcher M. (2020) professional athletes have poorer sleep quality and sleep hygiene compared with an age-matched cohort. Clin J Sport Med

9. Leeder J, Glaister M, Pizzoferro K, Dawson J, Pedlar C (2012) Sleep duration and quality in elite athletes measured using wristwatch actigraphy. J Sports Sci 30(6):541-545

10. Vitale KC, Owens R, Hopkins SR, Malhotra A (2019) Sleep hygiene for optimizing recovery in athletes: review and recommendations. Int J Sports Med 40(8):535-543

11. Luke A, Lazaro RM, Bergeron MF, Keyser L, Benjamin H, Brenner J et al (2011) Sports-related injuries in youth athletes: is overscheduling a risk factor? Clin J Sport Med 21(4):307-314

12. Chennaoui M, Arnal PJ, Sauvet F, Leger D (2015) Sleep and exercise: a reciprocal issue? Sleep Med Rev 20:59-72

13. Milewski MD, Skaggs DL, Bishop GA, Pace JL, Ibrahim DA, Wren TA et al (2014) Chronic lack of sleep is associated with increased sports injuries in adolescent athletes. J Pediatr Orthop 34(2):129-133

14. Nedelec M, Halson S, Delecroix B, Abaidia AE, Ahmaidi S, Dupont G (2015) Sleep hygiene and recovery strategies in elite soccer players. Sports Med 45(11):1547-1559

15. Fullagar HH, Skorski S, Duffield R, Hammes D, Coutts AJ, Meyer T (2015) Sleep and athletic performance: the effects of sleep loss on exercise performance, and physiological and cognitive responses to exercise. Sports Med 45(2):161-186
16. Brauer AA, Athey AB, Ross MJ, Grandner MA (2019) Sleep and health among collegiate student athletes. Chest 156(6):1234-1245

17. Knufinke M, Nieuwenhuys A, Geurts SAE, Coenen AML, Kompier MAJ (2018) Self-reported sleep quantity, quality and sleep hygiene in elite athletes. J Sleep Res 27(1):78-85

18. Partinen M, Gislason T (1995) Basic nordic sleep questionnaire (BNSQ): a quantitated measure of subjective sleep complaints. J Sleep Res 4(S1):150-155

19. Tuomilehto H, Peltonen M, Partinen M, Seppa J, Saaristo T, Korpi-Hyovalti E et al (2008) Sleep duration is associated with an increased risk for the prevalence of type 2 diabetes in middleaged women - the FIN-D2D survey. Sleep Med 9(3):221-227

20. Tuomilehto H, Peltonen M, Partinen M, Lavigne G, Eriksson JG, Herder C et al (2009) Sleep duration, lifestyle intervention, and incidence of type 2 diabetes in impaired glucose tolerance: the finish diabetes prevention study. Diabetes Care 32(11):1965-1971

21. van Selms M, Kroon J, Tuomilehto H, Peltomaa M, Savolainen A, Manfredini D et al (2020) Self-reported sleep bruxism among Finnish symphony orchestra musicians: associations with perceived sleep-related problems and psychological stress. Cranio $30: 1-8$

22. Filipas L, Ferioli D, Banfi G, La Torre A, Vitale JA (2021) Single and combined effect of acute sleep restriction and mental fatigue on basketball free-throw performance. Int J Sports Physiol Perform 12:1-6

23. McClure DJ, Zuckerman SL, Kutscher SJ, Gregory AJ, Solomon GS (2014) Baseline neurocognitive testing in sports-related concussions: the importance of a prior night's sleep. Am J Sports Med 42(2):472-478

24. Kostyun RO, Milewski MD, Hafeez I (2015) Sleep disturbance and neurocognitive function during the recovery from a sport-related concussion in adolescents. Am J Sports Med 43(3):633-640

25. Watson AM (2017) Sleep and athletic performance. Curr Sports Med Rep 16(6):413-418

26. Watson A, Johnson M, Sanfilippo J (2020) Decreased sleep is an independent predictor of in-season injury in male collegiate basketball players. Orthop J Sports Med 8(11):2325967120964481

27. Bergeron MF, Mountjoy M, Armstrong N, Chia M, Cote J, Emery CA et al (2015) International olympic committee consensus statement on youth athletic development. Br J Sports Med 49(13):843-851

28. Miles KH, Clark B, Fowler PM, Miller J, Pumpa KL (2019) Sleep practices implemented by team sport coaches and sports science support staff: a potential avenue to improve athlete sleep. J Sci Med Sport 22(7):748-752

29. Halson SL (2014) Sleep in elite athletes and nutritional interventions to enhance sleep. Sports Med 44(Suppl 1):S13-23

30. Sargent C, Lastella M, Halson SL, Roach GD (2014) The impact of training schedules on the sleep and fatigue of elite athletes. Chronobiol Int 31(10):1160-1168

31. Bonato M, Merati G, La Torre A, Saresella M, Marvetano I, Banfi $\mathrm{G}$ et al (2020) Effect of acute sleep hygiene on salivary cortisol level following a late night soccer-specific training session. J Sports Sci Med 19(1):235-236

32. Davies DJ, Graham KS, Chow CM (2010) The effect of prior endurance training on nap sleep patterns. Int J Sports Physiol Perform 5(1):87-97

33. Arnal PJ, Lapole T, Erblang M, Guillard M, Bourrilhon C, Leger D et al (2016) Sleep extension before sleep loss: effects on performance and neuromuscular function. Med Sci Sports Exerc 48(8):1595-1603

34. Dundar Y, Boland A, Strobl J, Dodd S, Haycox A, Bagust A et al (2004) Newer hypnotic drugs for the short-term management of insomnia: a systematic review and economic evaluation. Health Technol Assess 8(24):1-125 
35. Brown GA, Veith S, Sampson JA, Whalan M, Fullagar HHK (2020) Influence of training schedules on objective measures of sleep in adolescent academy football players. J Strength Cond Res 34(9):2515-2521

36. Vitale JA, Banfi G, Galbiati A, Ferini-Strambi L, La Torre A (2019) Effect of a night game on actigraphy-based sleep quality and perceived recovery in top-level volleyball athletes. Int J Sports Physiol Perform 14(2):265-269
Publisher's Note Springer Nature remains neutral with regard to jurisdictional claims in published maps and institutional affiliations. 